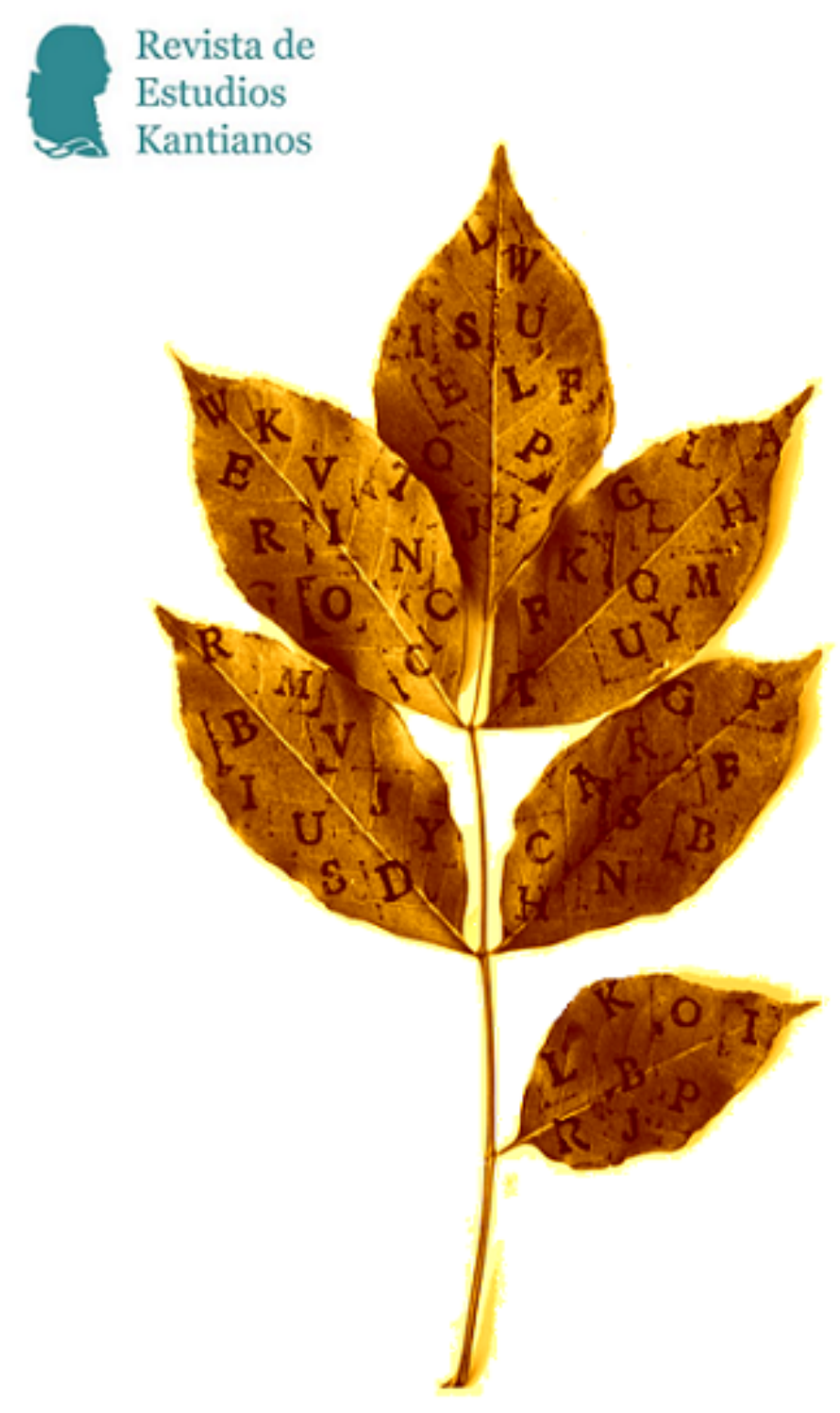


Revista de Estudios Kantianos 


\section{Revista de Estudios Kantianos}

Publicación internacional de la Sociedad de Estudios Kantianos en Lengua Española Internationale Zeitschrift der Gesellschaft für Kant-Studien in Spanischer Sprache

International Journal of the Society of Kantian Studies in the Spanish Language

\section{Dirección}

Pedro Jesús Teruel, Universitat de València

pedro.teruel@uv.es

Hernán Pringe, CONICET-Universidad de Buenos Aires/

Universidad Diego Portales, Santiago de Chile

hpringe@gmail.com

\section{Secretario de edición}

Fernando Moledo, Universidad de Buenos Aires - CONICET

fernandomoledo@filo.uba.ar

\section{Secretaria de calidad}

Marcela García, Universidad de Morelia, México

garciar.marcela@gmail.com

\section{Editores científicos}

Jacinto Rivera de Rosales, UNED, Madrid

Claudia Jáuregui, Universidad de Buenos Aires

Vicente Durán, Pontificia Universidad Javeriana, Bogotá

Julio del Valle, Pontificia Universidad Católica del Perú, Lima

Jesús Conill, Universitat de València

Gustavo Leyva, Universidad Autónoma de México, México D. F.

María Xesús Vázquez Lobeiras, Universidade de Santiago de Compostela

Wilson Herrera, Universidad del Rosario, Bogotá

Pablo Oyarzun, Universidad de Chile, Santiago de Chile

Paula Órdenes Azúa, Universität Heidelberg 


\section{Comité científico}

Juan Arana, Universidad de Sevilla

Reinhardt Brandt, Philipps-Universität Marburg

Mario Caimi, Universidad de Buenos Aires

Monique Castillo, Université de Paris-Est

Adela Cortina, Universitat de València

Bernd Dörflinger, Universität Trier

Norbert Fischer, Universität Eichstätt-Ingolstadt

Miguel Giusti, Pontificia Universidad Católica del Perú

Dulce María Granja, Universidad Nacional Autónoma de México

Christian Hamm, Universidad Federal de Santa María, Brasil

Dietmar Heidemann, Université du Luxembourg

Otfried Höffe, Universität Tübingen

Claudio La Rocca, Università degli Studi di Genova

Juan Manuel Navarro Cordón, Universidad Complutense, Madrid

Carlos Pereda, Universidad Nacional Autónoma de México

Gustavo Pereira, Universidad de la República, Uruguay

Ubirajara Rancan de Azevedo, Universidade Estadual Paulista, Brasil

Margit Ruffing, Johannes Gutenberg-Universität Mainz

Gustavo Sarmiento, Universidad Simón Bolívar, Venezuela

Sergio Sevilla, Universitat de València

Roberto Torretti, Universidad Diego Portales, Santiago de Chile

Violetta Waibel, Universität Wien

Howard Williams, University of Aberystwyth

Allen W. Wood, Indiana University

Diseño, revisión de estilo y maqueta

Josefa Ros Velasco, Harvard University, Cambridge (MA)

\section{Corrector}

Aldo Perán, Universidad Diego Portales, Santiago de Chile

\section{Entidades colaboradoras}

Sociedad de Estudios Kantianos en Lengua Española (SEKLE)

Departament de Filosofia de la Universitat de València

Instituto de Humanidades, Universidad Diego Portales

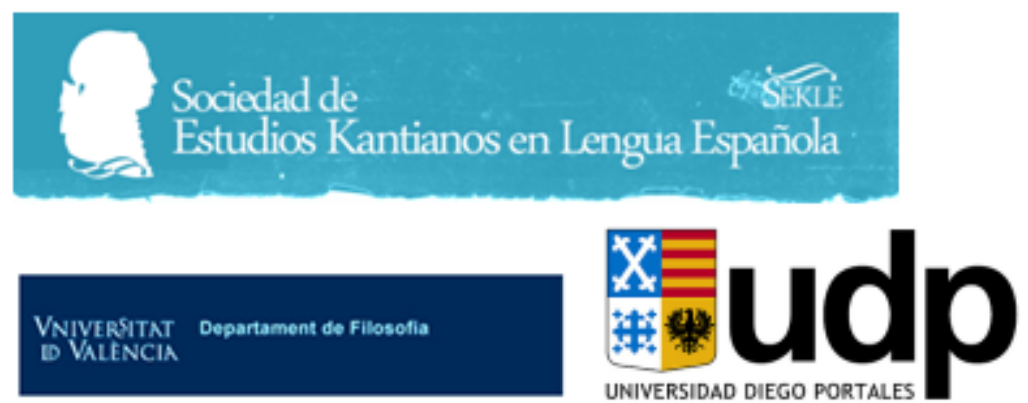




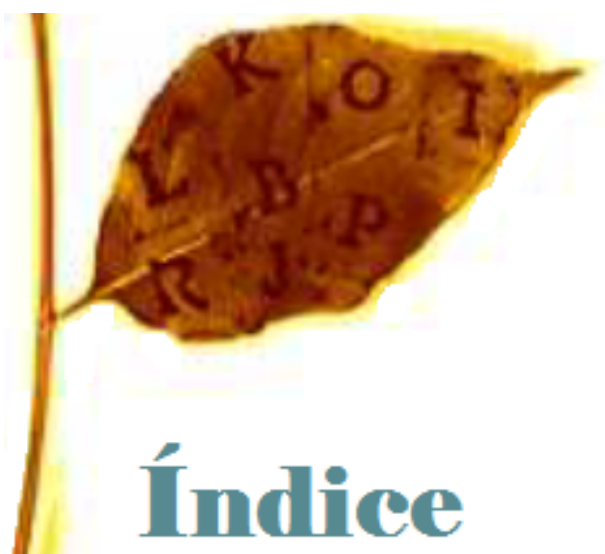

\section{Artículos}

125 Los deberes del amor en la doctrina kantiana de la virtud Bernd Dörflinger

DOI 10.7203/REK.2.2.10807

135 Towards a new conception of metaphysics: Lambert's criticism on Wolff's mathematical method

Gesa Wellmann

DOI 10.7203/REK.2.2.10724

149 Acerca del alcance objetivo de las prescripciones metodológicas de la función regulativa de la razón teórica en la Crítica de la razón pura de Kant

Martín Arias Albisu

DOI 10.7203/REK.2.2.8432

168 Formas de autoconciencia en la "Reflexión de Leningrado"

Matías Hernán Oroño

DOI 10.7203/REK.2.2.8799

179 Kants Konzeption kosmologischer Freiheit - ein metaphysischer Rest?

Christian Krijnen

DOI 10.7203/REK.2.2.10407

\section{Informe}

196 VII Coloquio Multilateral-Kant 2017

Paula Órdenes Azúa

DOI 10.7203/REK.2.2.10756 


\section{Reseñas}

200 Alfredo Ferrarin: Il pensare e l'io. Hegel e la critica di Kant. Roma, Carocci Editore, 2016, 244 pp. ISBN: 978-88-430-8246-9.

Luigi Filieri

DOI 10.7203/REK.2.2.10764

205 Mario Caimi, Ileana Beade, José González Ríos, Macarena Marey, Fernando Moledo, Mariela Paolucci, Hernán Pringe y Marcos Thisted: Diccionario de la filosofía crítica kantiana. Buenos Aires, Colihue, 2017, 507 pp. ISBN: 978-950-563-450-7.

Miguel Herszenbaun

DOI 10.7203/REK.2.2.10499

210 Paula Órdenes Azúa y Daniela Alegría: Kant y el Criticismo: pasado, presente, y ifuturo?, Porto Alegre, Editora Fi, 2015, 303 pp. ISBN: 978-85-66923-52-0.

Constanza Terra

DOI 10.7203/REK.2.2.10777

212 Juan Ormeño Karzulovic y Miguel Vatter (eds.): Forzados a ser libres. Kant y la teoría republicana del derecho. Santiago, Fondo de Cultura Económica, 2017, 243 pp. ISBN: 978956-289-149-3.

Cristóbal Olivares

DOI 10.7203/REK.2.2.10762

215 Immanuel Kant (ed. y trad. Gonzalo Serrano): La Deducción trascendental y sus inéditos, 1772-1788. Bogotá, Universidad Nacional de Colombia, 2014, 321 pp. ISBN: 978-95-876195-39.

Pedro Stepanenko

DOI 10.7203/REK.2.2.10763

\section{Semblanza}

220 Juan Adolfo Bonaccini (16 de mayo de 1965 / 10 de julio de 2016)

Daniel Omar Perez

DOI 10.7203/REK.2.2.10783

\section{Convocatorias y normas para autores}

223 Kant en México

DOI 10.7203/REK.2.2.10863

224 IV Congreso Internacional de la SEKLE, Valencia, 2018

DOI 10.7203/REK.2.2.10863

227 VIII Coloquio Multilateral-Kant 2018

DOI 10.7203/REK.2.2.10863

229 Normas para autores

DOI 10.7203/REK.2.2.10863 


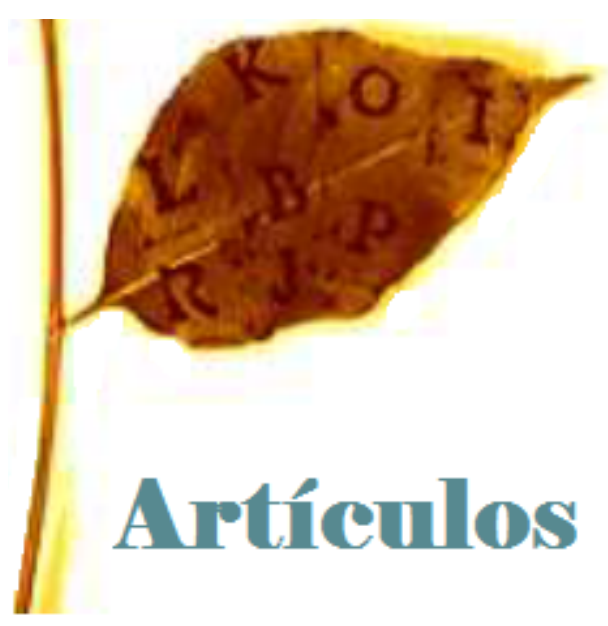




\title{
Kants Konzeption kosmologischer Freiheit - ein metaphysischer Rest?
}

\author{
Christian KRIJNEN ${ }^{1}$
}

\begin{abstract}
Die deutschen Idealisten waren der Auffassung, Kant habe mit seiner transzendentalen Umwälzung der Begründungsproblematik eine Revolution in der philosophischen Denkungsart in Gang gesetzt, die es weniger aufzuhalten als vielmehr dadurch zu vollbringen gelte, daß die Voraussetzungen oder ,Fundamente der Kantischen Philosophie selbst kritisch in den Blick genommen würden. Zu diesen Voraussetzungen gehört zweifelsohne Kants Architektonik der Vernunft im allgemeinen und die Stellung, die dem Freiheitsbegriff dabei zukommt, im besonderen. Es wird gezeigt, daß Kants Bestimmung kosmologischer oder transzendentaler Freiheit nicht so sehr einen sicheren Ausgangspunkt für Erkundungen im Rahmen der praktischen Philosophie etabliert als vielmehr zunächst eigens zum Thema gemacht werden sollte. Dann wird sichtbar, daß das Profil der kritischen Freiheitskonzeption Kants stark durch die deutsche Schulmetaphysik des 18. Jh.'s geprägt ist. Damit geraten allerlei Vorentscheidungen und unausgewiesene Konstellationen dieses Profils betreffend in den Blick; Vorentscheidungen und Konstellationen, die sich gemäß Hegels Analyse auch gar nicht ausweisen lassen, sondern den Übergang zu einem allgemeineren Freiheitsbegriff als dem transzendentalen oder kosmologischen Kants erforderlich machen. Die Folgen dieses Sachverhalts werden abschließend illustriert durch eine Betrachtung der Transzendentalphilosophie Bruno Bauchs, des wohl besten KantKenners des Neukantianismus.
\end{abstract}

Keywords: Bauch, Freiheit, Hegel, Kant, Metaphysik, Spontaneität, Willkür

\section{La concepción kantiana de la libertad: ¿un resto metafísico?}

\begin{abstract}
Resumen
Los idealistas alemanes entendían que Kant, con su cambio radical en la problemática de la fundamentación, puso en marcha una revolución del modo de pensar filosófico que no se debía impedir, sino completar, considerando críticamente las presuposiciones o 'fundamentos' de la filosofía crítica misma. Entre estas presuposiciones se cuenta, sin dudas, la arquitectónica kantiana de la razón en general y, en particular, la posición que le corresponde en ella al concepto de la libertad. Al respecto se señala que la determinación kantiana de la libertad cosmológica o trascendental no establece un punto de partida seguro para las investigaciones en el marco de la filosofía práctica y que primero se la debería hacer adecuada para ello. Al hacerlo, se vuelve claro que el perfil de la concepción crítica kantiana de la libertad está influenciado por la filosofía escolástica del siglo XVIII. En ese sentido, se hacen visibles varias posiciones previas y constelaciones injustificadas, correspondientes a ese perfil; posiciones y constelaciones que, de acuerdo con el análisis de Hegel, tampoco se pueden justifican, sino que hacen necesario el tránsito a un concepto de libertad más general que el de Kant. Las consecuencias de esto se ilustran mediante un examen de la filosofía trascendental de Bruno Bauch, el mayor conocedor de la filosofía de Kant en el neokantismo.
\end{abstract}

Palabras clave: Bauch, libertad, Hegel, Kant, metafísica, espontaneidad, arbitrio

1. Kosmologische Freiheit als Problem

Wenn etwas den deutschen Idealismus zusammenhält, dann der Versuch, im Ausgang von Kants Transzendentalphilosophie zu einem sowohl umfassenderen als auch tieferen Konzept von Freiheit zu

\footnotetext{
${ }^{1}$ Vrije Universitet Amsterdam.
} 
gelangen. Dieser Versuch ist mit Kants transzendentaler Wende in der philosophischen Begründungsthematik intrinsisch verbunden, besteht doch deren Sinn darin, die Vernunft, oder wie es im Diskurs auch heißt: die Subjektivität, als Quelle aller Geltung, aller Normativität menschlicher Tätigkeit und damit aller Objektivität oder Gegenständlichkeit auszuweisen. Das Denken, Tun und Lassen des Menschen gilt für Kant als Denker der Moderne nicht mehr als fremdbestimmt, heteronom, sondern als selbstbestimmt, autonom, befreit also von so oder so gearteten externen Mächten als Bestimmungsgründen. Der Begriff der Freiheit muss in einer modernen Transzendentalphilosophie folglich eine prominente Rolle spielen.

Zugleich erscheint Kants Freiheitsbegriff, so wie er historisch vorliegt (also ohne ihn mit allerlei Vor- und Nachsätzen auszustatten) unzulänglich. Den systematisch interessierten Interpreten ist schon lange aufgefallen, dass Kants Freiheitsbegriff ein praktisches Profil eignet, Kants Konzeption kosmologischer Freiheit geradezu Vorblick nimmt auf eine Metaphysik der praktischen Vernunft endlicher Subjekte. Schon im Nachweis der Denkmöglichkeit der ,kosmologischen“ Freiheitskausalität wird klar, dass es Kant vor allem um die Möglichkeit ,moralischer' Freiheit für unser ,Handeln' geht (der die kosmologische oder transzendentale Freiheit logisch vorhergeht: KrV, B561 f., vgl. 831). ${ }^{2}$ Kant modelliert Freiheit in der dritten Antinomie, zunächst die kosmologische und auf sie gründend die praktische, entsprechend als ein ,Vermögen', Ursache von Wirkungen zu sein, näherhin: als ein Vermögen, eine Reihe von Wirkungen ,von selbst', ,spontan` anzufangen. Diese vermögenstheoretische Modellierung lässt, worum es Kant geht, der schon im kosmologischen Kontext die Freiheit ,im praktischen Verstande' ins Zentrum rückt, den Menschen als Autor seiner Handlungen verstehen: nicht bloß als Wirkung einer Naturkausalität, nicht als bloßes Objekt, sondern eben als Subjekt.

Ebendieses praktische Profil der Freiheitsantinomie steht in einem durchaus schroffen Kontrast zur systematischen Problemstellung der dritten Antinomie. Kants transzendentaler Idealismus und die damit einhergehende Unterscheidung zweier Welten, der Welt als Erscheinung und der der Dinge an sich, der phänomenalen und der noumenalen Welt, macht die Komptabilität von Natur und Freiheit nicht nur einsichtig, sondern erweist das kosmologische Verhältnis beider zugleich so, dass die phänomenale Welt in der noumenalen gründet, dass Freiheit Ursache der Natur ist, die intelligible Welt die Sinnenwelt bewirkt. Freiheit im kosmologischen Verstande erweist sich als (transzendentalphilosophisch verstandener) Seinsgrund: als Grund der Erscheinungswelt.

\footnotetext{
${ }^{2}$ Für Hans Friedrich Fulda: „Freiheit als Vermögen der Kausalität und als Weise, bei sich selbst zu sein“. In: Inmitten der Zeit. Beiträge zur europäischen Gegenwartsphilosophie (FS M. Riedel), hg. von Thomas Grethlein und Heinrich Leitner (Würzburg 1996: 47-63, 55), vgl. 61, ist Kants Idee von Freiheit in Verbindung mit der allgemeinen Naturnotwendigkeit, also Kants kosmologische Freiheitsidee, vom Vorgriff auf eine Metaphysik der praktischen Vernunft endlicher Subjekte geleitet. Hans Wagner wird nicht müde zu betonen, dass es die Möglichkeit der Freiheitskausalität menschlicher Handlungen ist, die Kant in der dritten Antinomie beschäftigt (Hans Wagner: „Die kosmologische Antithetik und ihre Auflösung in Kants Kr.d.r.V“. In: Zu Kants Kritischer Philosophie, hg. von Bernward Grünewald und Hariolf Oberer, Würzburg 2008: 82-97, 85), die Auflösung der dritten Antinomie unter dem „Hauptgedanken“, dem „Hauptziel“ der Möglichkeit praktischer Freiheit steht (ebd. 95. vgl. auch Hans Wagner: „Kants ergänzende Überlegungen zur Möglichkeit von Freiheit im Rahmen der Auflösung der dritten Antinomie“. In: $Z u$ Kants Kritischer Philosophie, hg. von Bernward Grünewald und Hariolf Oberer (Würzburg 2008: 98-106, 99, 104). Vielmehr noch als um die Möglichkeit einer gegen alle Naturkausalität stehenden kosmologischen Spontan- oder Freiheitskausalität, gehe es Kant um die Möglichkeit moralischer Freiheit für menschliches Handeln (ebd. 101). „Eigentlich“ (ebd. 103) treibe Kant die Doppelnatur des Menschen als homo phaenomenon und homo noumenon, und damit als naturkausal bedingtes wie als vernunftkausal bedingtes Wesen um. Otfried Höffe: Kants Kritik der reinen Vernunft. Die Grundlegung der modernen Philosophie (München 2003: 254), spricht von einem ,Leitziel', das die dritte Antinomie allerdings nur ,indirekt' thematisiert. Werner Flach: Die vielfältigen Aspekte des Freiheitsbegriffs in der Philosophie Kants (unveröff. Manuskript 2016), hat unlängst zwar versucht, Freiheit bei Kant als Spontankausalität von Intelligibilität zu unterscheiden, muss aber gleichwohl eingestehen, dass Kant die der Spontaneität eigene Unbedingtheit gleich als Intelligibilität charakterisiert. Freilich macht Flach die kosmologische Freiheit nicht eigens thematisch: er legt primär Kants praktische Profilierung aus und unterscheidet dabei das Erkenntnisinteresse, das zivile Interesse, das sittliche Interesse und das ästhetische Interesse. Er setzt dabei eine Auslegung fort, die unlängst dokumentiert ist in Werner Flach: Kant $z u$ Geschichte, Kultur und Recht. Hrsg. von Wolfgang Bock (Berlin 2015). — Kant wird zitiert nach Kants gesammelte Schriften $($ Akademie-Ausgabe $=\mathrm{AA})$, Band, Seite(n); KrV gemäß der Originalpaginierung. $\mathrm{KrV}=$ Kritik der reinen Vernunft $; \mathrm{KpV}=$ Kritik der praktischen Vernunft; $\mathrm{KU}=$ Kritik der Urteilskraft .
} 
Die Verquickung, um nicht zu sagen: Kontamination der kosmologischen Dimension mit der praktischen Dimension der Freiheit bedarf der Aufhellung. Die skizzierte Konstellation führt systematisch gesehen nämlich zu einer Kantischen Hypothek, die zu tilgen in der kantianisierenden Transzendentalphilosophie noch aussteht, die Hegel jedoch paradigmatisch geleistet hat. Während sich die Kant-Forschung vorwiegend mit Kants Nachweis der Denkbarkeit der Freiheit zufrieden gibt und sodann dessen Beweis(e) für die objektive Realität des Freiheitsbegriffs bzw. dessen Verästelung in Moral, Recht und Tugend nachspürt, hat die Transzendentalphilosophie des südwestdeutschen Neukantianismus bis in die neuere Transzendentalphilosophie von Hans Wagner und Werner Flach hinein aus der Bestimmung von Freiheit als Vermögen eigengesetzlicher Kausalität des tätigen Subjekts ein axiotisches Grundverhältnis gestrickt, das das fundierende Verhältnis für die gesamte Welt des Menschen ausmacht und sich in verschiedene Kultur- oder Geltungssphären spezifiziert Wissenschaft, Moral, Recht, Kunst usw. Hegel problematisiert und kritisiert das kosmologische, von Kant auch transzendental genannte Freiheitsverständnis und qualifiziert es als unzureichend: der Begriff selbst ist ihm das Freie, und der Begriff verursacht nicht etwas anderes, als er selbst ist, sondern manifestiert sich in allem, was irgendwie ist, ist bei sich in seinem Anderen. Hegel nimmt dabei sowohl den kosmologischen Impetus der Freiheit als Ursprung der Erscheinungswelt als auch Kants höchstes Prinzip alles Verstandesgebrauchs, die synthetische Einheit der Apperzeption, radikal ernst. $^{3}$ - Wenn im folgenden Kants Freiheitslehre kritisch betrachtet wird, so ist diese Betrachtung im Übrigen geleitet von der Überzeugung ihrer überragenden Aktualität im Vergleich zu allerlei kursierenden Naturalismen, Utilitarismen, Tugendethiken u. dgl. Hegels philosophische Höhenflüge bilden die Herausforderung, nicht die Niederungen des philosophischen Alltags.

Es gilt daher, Kants Bestimmung kosmologischer oder transzendentaler Freiheit eigens zum Thema zu machen, statt ihn vorschnell als gesichert anzunehmen bzw. praktisch auszuschalten. Ein unbefangener Blick wundert sich vielmehr über die Bestimmungen von Freiheit, die in die kosmologische Antinomie hineinschneien, mögen sie auch gerade von einer modernen, willensorientierten Konzeption von Freiheit durchaus eine prima facie Plausibilität haben: ausgewiesen als Bestimmungen von Freiheit sind sie damit gerade nach Kants kritischen Maßstäben noch lange nicht. Dies ist umso bedeutsamer, als Kants Freiheitskonzeption, wie angedeutet, durchaus praktisch präfiguriert ist. Mit Blick auf das Argumentationsziel und den Argumentationsgang der Kritik der reinen Vernunft mag man dies noch als unwesentlich hinnehmen. Gleichwohl bildet gerade das in der dritten Antinomie erreichte Ergebnis, die Denkbarkeit der Freiheit als Unabhängigkeit von allen bestimmenden Ursachen der phänomenalen Welt und Bestimmbarkeit durch Ursachen der intelligiblen Welt, d.h. die Möglichkeit der Selbstbestimmung statt der durchgängigen Fremdbestimmung, den Ausgangspunkt der kritischen Grundlegung der praktischen Vernunft. ${ }^{4}$ Ohne kosmologische oder transzendentale Freiheit qua Vermögen, eine Reihe von sukzessiven Dingen oder Zuständen in der Welt von selbst anzufangen, gibt es keine praktische Freiheit als Vermögen willentlicher Selbstbestimmung, sondern nur einen unverbrüchlichen Determinismus. Damit aber meldet sich in aller Härte die kritische Forderung nach Rechenschaftslegung transzendentaler Begriffe, noch abgesehen von der Tatsache, dass Freiheit einer der beiden Grundbegriffe der gesamten Kantischen Architektonik der Vernunft ist. Problematisch wird also weniger die Denkbarkeit der Freiheit, sondern vielmehr dass Freiheit ebenjener Sachverhalt ist, als den Kant ihn in seinem transzendentalen oder kosmologischen Freiheitsbegriff in Anspruch nimmt. Dies betrifft

\footnotetext{
${ }^{3}$ Vgl. zu Hegels Lehre von der Freiheit des Begriffs neuerdings Hans Friedrich Fulda: „Der eine Begriff als das Freie und die Manifestationen der Freiheit des Geistes“. In: Hegel - 200 Jahre Wissenschaft der Logik, hg. von Anton Friedrich Koch, Friedrike Schick u. a. (Hamburg 2014: 15-41); Franz Knappik: Im Reich der Freiheit. Hegels Theorie autonomer Vernunft (Berlin 2013); Christian Krijnen: „Freiheit als ursprüngliche Einheit der Vernunft. Hegels begriffslogische Lösung eines Kantischen Problems“. In: Natur und Geist hg. von Wolfgang Neuser und Pirmin Stekeler-Weithofer (Würzburg 2016: 25-52).

${ }^{4}$ - wie Kant selbst Eingangs der Kritik der praktischen Vernunft durch seine Bezugnahme auf die dritte Antinomie unterstreicht $(\mathrm{KpV}, \mathrm{AA} \mathrm{V} \mathrm{15).}$
} 
zunächst die Bestimmtheit der Freiheit, Ursprung der Erscheinungswelt zu sein; sie ermöglicht allererst den praktischen Freiheitsbegriff.

Tatsächlich läßt sich das Profil von Kants kritischer Freiheitskonzeption im Allgemeinen und das der dritten Antinomie im Besonderen aus ihrer Einbettung in der deutschen Schulphilosophie des 18. Jahrhunderts verstehen. ${ }^{5}$ Sogar die makroskopische Andeutungen Kants bezüglich seiner philosophiegeschichtlichen Selbstpositionierung im Spektrum von „Physiokratie“ (KrV, B478), „Epikureism“ und „Platonism“ (KrV, B499) ${ }^{6}$ haben Vorlagen im schulmetaphysischen Bildungsgut der Zeit. ${ }^{7}$ Das soll keineswegs heißen, dass das Profil der Kantischen Freiheitskonzeption keine von ihrer historischen Situierung unabhängige Plausibilität für sich hat, sondern dass es ungemein aufschlußreich ist, Kants transzendentalen oder kosmologischen Freiheitsbegriff im Kontext der damaligen Diskussionslage zu betrachten. Dies betrifft vor allem das Profil der Kantischen Freiheitslehre selbst. Es geraten allerlei Vorentscheidungen und unausgewiesene Konstellationen dieses Profils betreffend in den Blick ${ }^{8}$ - Vorentscheidungen und Konstellationen, die sich gemäß Hegels Analyse auch gar nicht ausweisen lassen, sondern den Übergang zu einem allgemeineren Freiheitsbegriff als dem transzendentalen oder kosmologischen Kants erforderlich machen. Der kosmologische Freiheitsbegriff als Ursprung der Erscheinungswelt ist, bei näherer Betrachtung, vorschnell der Schulmetaphysik entnommen, anstatt ihm transzendental auf den Grund zu gehen. Spontaneität bzw. Freiheit wird entsprechend zu einem schlechterdings fundamentalen Kernthema des nachkantischen Idealismus.

Im Folgenden will ich zunächst Grundzüge der Diskussion der Zeit grob skizzieren, jedenfalls was das für meine These Wichtigste betrifft (2). Sodann kommt Hegels Transformation des Freiheitsbegriffs zur Sprache (3), bevor abschließend am Beispiel Bruno Bauchs das axiotische Grundverhältnis der kantianisierenden Transzendentalphilosophie problematisiert wird (4).

\section{Kant im Kontext der Schulmetaphysik}

Die Debatte über den Spinozismus mag hier als Fluchtpunkt fungieren. Erstens bildet die Auseinandersetzung zwischen der Philosophie Wolffs und dem Hallenser Pietismus zweifelsohne eine der erbittertsten Geistesdispute des 18. Jahrhunderts. Der sachliche Kern des Streits betrifft die Frage: Fatalismus oder Freiheit? Wolff wurde von Lange vorgeworfen, mit einer mechanistischen Welterklärung à la Spinoza (und Leibniz), die Freiheit des Menschen preiszugeben; fatalis necessitas,

\footnotetext{
${ }^{5}$ Vgl. zu Kants Schlüsselbegriffen Spontaneität und Willkür vor allem die glänzende Arbeit von Katsutoshi Kawamura: Spontaneität und Willkür. Der Freiheitsbegriff in Kants Antinomienlehre und seine historischen Wurzeln (Stuttgart-Bad Cannstatt 1996). Vgl. auch: Katsutoshi Kawamura: „Eine begriffsgeschichtliche Skizze der "Willkür" im 18. Jahrhundert. Wolff, Wagner, Feder und Kant". In: Recht und Frieden in der Philosophie Kants. Akten des X. Internationalen Kant-Kongresses III, hg. von Valerio Rohden, Ricardo Terra u. a. (Berlin 2008: 173-181); Reinhard Finster: Spontaneität, Freiheit und unbedingte Kausalität bei Leibniz, Crusius und Kant“. In: Studia Leibnitiana 14 (1982: 266-277); Reinhard Finster: Spontaneität und Freiheit. Eine Untersuchung zu Kants theoretischer Philosophie unter Berücksichtigung von Leibniz, Wolff und Crusius. Univ. Diss. (Trier 1984); Clemens Schwaiger: Alexander Gottlieb Baumgarten. Ein intellektuelles Porträt. Studien zur Metaphysik und Ethik von Kants Leitautor (Stuttgart-Bad Cannstatt 2011).

${ }^{6}$ Vgl. dazu auch unter Berücksichtigung anderer antiker Positionen Heinz Heimsoeth: „Zum kosmotheologischen Ursprung der Kantischen Freiheitsantinomie“. In: Kant-Studien 56 (1966: 206-229).

${ }^{7}$ Vgl. K. Kawamura: Spontaneität und Willkür, a.a.O. [Anm. 5] $124 \mathrm{f}$.

${ }^{8}$ Georg Geismann: „Kant über Freiheit in spekulativer und in praktischer Hinsicht“. In: Kant und kein Ende. Band 1: Studien zur Moral-, Religions- und Geschichtsphilosophie (Würzburg 2009: 119-142), bietet eine wohl dokumentierte und lehrreiche Analyse von Kants Bestimmung transzendentaler und praktischer Freiheit; er stellt allerdings den Entwicklungsgang von Kants Denken über Freiheit nicht in Rechnung. Vielmehr bemüht er sich um die Herstellung einer Kontinuität. Dabei ist schon der praktische Freiheitsbegriff der Kritik der reinen Vernunft unkritisch und entsprechend ohne Nachweis seiner objektiven Realität. Diesen Nachweis liefert Kant erst durch das Faktumtheorem der reinen praktischen Vernunft in der Kritik der praktischen Vernunft, womit er zugleich den transzendentalen Freiheitsbegriff in seiner objektiven Sachhaltigkeit rechtfertigt (und nicht in seiner bloßen Denkbarkeit, wie in der dritten Antinomie der Kritik der reinen Vernunft). Geismann will unbedingt vermeiden, Wasser auf die Mühlen der „Flickwerk-Anhänger“ (ebd. 134) fließen zu lassen. Gleichwohl hat nicht nur Kants Freiheitstheorie innerhalb der kritischen Periode grundlegende Änderungen erfahren, sondern diese Änderungen schreiben zugleich einen Entwicklungsgang fort, der schon früh in Kants vor-kritischem Denken anhob.
} 
alles Geschehen sei unentrinnbar notwendig. ${ }^{9}$ Für die deutsche Aufklärungsphilosophie wurde die Freiheitsfrage durch diesen Disput zu einer Schicksalsfrage, die auch Kants Freiheitsantinomie der Kritik der reinen Vernunft problem- wie quellengeschichtlich - vermittelt besonders über Baumgartens Metaphysik - gespeist hat. Zum zweiten wird in diesem Disput auf ein ,fatalistisches Einheitskonzept reagiert, das gerade Hegel für seinen freiheitsphilosophischen Fortgang über Kant hinaus spekulativ eben als Freiheit umdeutet.

Kants Unterscheidung von transzendentaler oder kosmologischer Freiheit als ,absoluter Spontaneität“ (KrV, B474) und praktischer Freiheit als „freier Willkür“ oder ,arbitrium liberum“ (KrV, B561 f., 830, 836) hat ihre Vorlagen in der Schulmetaphysik. Beide Freiheitsbegriffe sind nicht nur unterschiedlicher historischer und problemgeschichtlicher Herkunft, sondern, was für meine Analyse von großer Bedeutung ist, der transzendentale Freiheitsbegriff selbst speist sich aus zwei unterschiedlichen Problemkontexten. ${ }^{10}$ Dadurch wird nämlich das bei Kant fortwährend wirksame praktische Profil der kosmologischen Freiheit als absoluter oder unbedingter Spontaneität verständlich.

Es betrifft zum einen den ,praktischen' Kontext philosophischer Reflexionen über Wahloder Willkürfreiheit, vor allem deren Stufung in i) ,Spontaneität' als Handlung, ii) ,Willkür` als Handlung nach Belieben und, iii), freie Willkür` als Handlung nach vernünftigem Belieben. Kants transzendentaler Freiheitsbegriff bildet aus dieser Perspektive eine Spezifikation der freien Willkür. Dergleichen Reflexionen über Willkürfreiheit finden sich in der empirischen Seelenlehre der damaligen Schulmetaphysik. Spontaneität und Willkür wurden hierzunächst einfach gleichgesetzt: Wolff übersetzt wirkungsmächtig Leibnizens ,Spontaneität‘ als selbstbestimmtes Handeln mit ,Willkür' und faßt ,Freiheit' als ,vernünftige Willkür' ${ }^{6}{ }^{11}$ bevor Friedrich Wagner und, für Kant wichtiger, Baumgarten Spontaneität und Willkür begrifflich trennen. Im Zuge Wagners unterscheidet Baumgarten drei Stufen der Selbsttätigkeit:

i) spontaneitas, d. h. Handlungen, die aus einem inneren zureichenden Grund erfolgen,

ii) Willkür bzw. arbitrium, d. h. das Vermögen nach eigenem Belieben zu begehren (oder zu verabscheuen),

iii.i) sinnliche Willkür bzw. arbitrium sensitivum als eine von sinnlichem Belieben bestimmte Willkür und

iii.ii) Freiheit bzw. arbitrium liberum als Vermögen, nach vernünftigem Belieben zu begehren (oder zu verabscheuen). ${ }^{12}$

Willkür ist hier also konzeptualisiert als eine besondere Art von Spontaneität und Freiheit wiederum als eine besondere Art der Willkür. Dass Kants transzendentaler Freiheitsbegriff problemgeschichtlich eine Innovation darstellt, verhindert nicht, dass auch die transzendentale Freiheit als eine besondere Art der Willkür gedacht ist, als „unbedingte Willkühr“ (Refl. 3860, AA XVII 316) eben, oder wie Kant in der Kritik der reinen Vernunft sagt, als „absolute Spontaneität“ (KrV, B474). Diese ist nicht bloß, wie die praktische Freiheit, unabhängig von sinnlichen Antrieben, sondern unabhängig von jeglichem äußeren Zwang, nicht von etwas abgeleitet, sondern „unbedingt“

${ }^{9}$ Vgl. zum Wolff-Lange-Streit: Albrecht Beutel: „Causa Wolffiana. Die Vertreibung Christian Wolffs aus Preußen 1723 als Kulminationspunkt des theologisch-politischen Konflikts zwischen halleschem Pietismus und Aufklärungsphilosophie“. In: Reflektierte Religion. Beiträge zur Geschichte des Protestantismus (Tübingen 2007: 125-169); Bruno Bianco: „Freiheit gegen Fatalismus. Zu Joachim Langes Kritik an Wolff“. In: Zentren der Aufklärung: I: Halle. Aufklärung und Pietismus, hg. von Norbert Hinske (Berlin 1989: 111-155); K. Kawamura: Spontaneität und Willkür, a.a.O. [Anm. 5] 25 ff., 131 ff.; C. Schwaiger: Baumgarten, a.a.O. [Anm. 5] $79 \mathrm{ff}$

${ }^{10}$ Vgl. dazu eingehendK. Kawamura: Spontaneität und Willkür, a.a.O. [Anm. 5].

${ }^{11}$ Christian Wolff: Vernünfftige Gedancken von Gott, der Welt und der Seele des Menschen, auch allen Dingen überhaupt. In: Gesammelte Werke I.2, hg. von Jean École et al. (Hildesheim, New York 1962 ff.), § $519 \mathrm{f}$.

${ }^{12}$ Alexander Gottlieb Baumgarten: Metaphysica. Ed. IV, 1757. In: Kants gesammelte Schriften. Bd. I-XXIX XIV, XV, XVII, hg. von Königlich-Preußische Akademie der Wissenschaften et al. (Berlin 1910 ff.), §§ 712 mit 719. 
(Refl. 3860, AA XVII 316), ursprünglich, „originalis“ (Refl. 4548, AA XVII 589), ,absolut“ (KrV, B474).

Zum anderen betrifft der transzendentale Freiheitsbegriff den ,theoretischen“ Kontext philosophischer Reflexionen über die Freiheit oder Selbsttätigkeit des Menschen im Ganzen des Weltgeschehens, also den Kontext der Kosmologie. In dieser Perspektive ist Kants transzendentaler Freiheitsbegriff eine Lösung für das Problem des ,Ursprungs‘ eben jenes Weltgeschehens. Indem Kant in seiner 1755er Habilitation Freiheit im kosmologischen Verstande zunächst in den Bahnen Wolffs denkt und entsprechend als Spontaneität aus einem inneren Grund, ${ }^{13}$ der selbst in der Reihe vorhergehender Gründe liegt, ist sein Denken über Freiheit von Anfang an mit dem Problem des Verhältnisses vom Satz des zureichenden oder bestimmenden Grundes zur Freiheit qua Entstehen ohne vorhergehenden Grund, also als schlechthin erster Ursache, befrachtet. Es wird ihm seit den 60er Jahren ausdrücklich zum Problem. Kants Lösung läuft bekanntlich auf die Unterscheidung von sensibler und intelligibler Welt hinaus: der Satz vom zureichenden Grund gilt als „Grund möglicher Erfahrung, nämlich der objectiven Erkenntniß der Erscheinungen in Ansehung des Verhältnisses derselben in Reihenfolge der Zeit“ (KrV, B246). Für die kosmologisch verstandene Freiheit gilt indes, dass sie als absolute Spontaneität oder transzendentale Freiheit keinen solchen vorhergehenden bestimmenden Grund hat, sondern davon unabhängig und folglich intelligibler Art ist.

Diese kosmologische Profilierung des Freiheitsproblems hängt eng mit dem Problem menschlicher Freiheit zusammen. Sie entzündet sich nämlich an der Wolff-Lange-Kontroverse, also am Fatalismusstreit. Schon Wolff denkt das Weltgeschehen nicht als gegründet in einer sich selbst verursachenden und notwendigen unendlichen Rückgangsreihe, sondern in einer mit Gott als schlechthin erster, extramundaner und frei wählender Ursache oder Kausalität abgeschlossenen und als Ganzes zufälligen Reihe. ${ }^{14}$ Gott ist der Urheber, das Unbedingte, hat das Vermögen, einen Zustand des Weltlaufs (bzw. diesen als solchen) von selbst anzufangen. Die schulphilosophischen Debatten in puncto kosmologischer Freiheit kreisen sodann um die Frage nach der Möglichkeit oder Unmöglichkeit, einen Rückgang ins Unendliche zu denken, sodass die praktische oder psychologische Dimension der Freiheit in den Hintergrund rückt. Gerade Baumgarten hat das Problem des unendlichen Rückgangs eingehend in seiner Metaphysik thematisiert. ${ }^{15}$ Das ens extramundanum als wirkende Ursache außerhalb der Welt ist unbedingt und notwendig, die Welt bedingt und zufällig; die Rückgangsreihe ist nicht unendlich, sondern hat ihren Grund außer sich, während diesem Grund das Vermögen eignet, einen Zustand des Weltlaufs überhaupt erst anzufangen. Die Welt ist daher nicht gedacht, wie bei Spinoza, als die Selbstentfaltung einer unendlichen Substanz. Gleichwohl bleibt undurchsichtig, wie Freiheit als Spontaneität und der Satz des zureichenden Grundes sich versöhnen lassen, d. h. wie die Freiheit des Menschen denkbar wird. Kants dritte Antinomie bietet eine kosmologische Lösung für dieses praktische Problem. An die Stelle des Schemas ens extramundanum - mundus bzw. ,Unbedingtes: Gott - Bedingtes: Mensch` tritt die Vernunft im Menschen. Kosmologische Freiheit ist entsprechend absolute Spontaneität.

Damit bildet der transzendentale Freiheitsbegriff zugleich auch, was Kant öfters betont und systematisch gänzlich schlüssig ist, den Boden für den praktischen Freiheitsbegriff. Hier wie dort ist der Satz vom zureichenden oder bestimmenden Grund maßgebend: dass und wie etwas ist, hat seine Ursache oder seinen Grund. Während die ontotheologischen schulmetaphysischen Vorgänger Kants das Problem von Spontaneität und vorhergehendem Grund durch den Rekurs auf ein ens extramundanum, d. h. Gott als sich selbst bestimmendes Wesen, versuchten zu lösen, erweist sich für

${ }^{13}$ Wolff faßt Spontaneität im Sinne von Leibniz. Unter Bezug auf Aristoteles heißt es bei Leibniz, eine Handlung ist spontan, wenn ihr Prinzip in dem Handelnden liegt (Gottfried Wilhelm Leibniz: Essais de théodicéesur la bonté de dieu, la liberté de l'homme et l'origine du mal. In: Die philosophischen Schriften von Gottfried Wilhelm Leibniz VI, hg. von Carl Immanuel Gerhardt (Hildesheim 1978), 296 (§ 301).

${ }^{14}$ C. Wolff: Deutsche Metaphysik, a.a.O. [Anm. 11] $§ 1080$ mit 579.

${ }^{15}$ A. G. Baumgarten: Metaphysica, a.a.O. [Anm. 12] $\S 380 \mathrm{f}$. 
Kant die Vernunft selbst als das Unbedingte und damit als transzendentale Freiheit, absolute Spontaneität. Freiheit als absolute Spontaneität ist das Vermögen, „einen Zustand von selbst anzufangen“ (KrV, B561, vgl. 474), also ein allgemeinerer Sachverhalt als „praktische“ Freiheit qua nicht-sinnliche Willkür, d. h. als eine Willkür, die „unabhängig von sinnlichen Antrieben, mithin durch Bewegursachen, welche nur von der Vernunft vorgestellt werden“, bestimmt werden kann (arbitrium liberum) (KrV, B830).

Die Unterscheidung von Spontaneität und Willkür ergibt sich dabei erst im Laufe der 60er Jahre. Freiheit ist für Kant zunächst auf Vernunft gegründete Willkür, wobei er sich an Baumgartens Einteilung der Selbsttätigkeit anlehnt (spontaneitas, arbitrium, liberum arbitrium) und Freiheit als arbitrium faßt. Dabei unterliegen freie Handlungen dem Satz vom Grunde, letztlich Gott. Freiheit als Unabhängigkeit von einem vorhergehend bestimmenden Grund kennt Kant vorerst noch nicht, sieht dann jedoch, dass Freiheit als Willkür bzw. unbedingte Willkür eine spontaneitas simpliciter talis, also eine schlechthin erste, unbedingte Spontaneität voraussetzt, sodass sich das Problem ergibt, wie eine solche unbedingte Willkür innerhalb der Reihe bestimmender Gründe auftreten kann (zumal wenn der Mensch das Geschöpf eines göttlichen Urhebers ist). In den 70er Jahren gelangt Kant dann zur terminologischen Unterscheidung von transzendentaler und praktischer Freiheit (arbitrium liberum), die Kant beide als Willkürfreiheit bezeichnet: Transzendentale Freiheit bezieht sich entsprechend auf jene Handlungen der Willkür, die „schlechthin spontan“ oder „ursprünglich“ sind (Refl. 4547, AA XVII 589), unabhängig von jeglicher äußeren Nötigung. Freiheit wird hier allerdings noch nicht in Spontaneität und Willkür unterschieden. In den späten 70er Jahren kommt es dann zu einer schärferen Unterscheidung von praktischer und transzendentaler Freiheit dahingehend, dass er die praktische Freiheit zur empirischen, die transzendentale hingegen zur rationalen Psychologie zählt. Diese thematisiert die Willkür nicht als Vermögen, sich nach (sinnlichen und vernünftigen) Gründen zu bestimmen, sondern als unbedingte oder absolute Willkür und damit als schlechthin erste Spontaneität oder unbedingte Ursache. Während der Rekurs auf ein principium externum, einen Urheber menschlicher Spontaneität, diese zu einer spontaneitas automatica macht, also zur „Freiheit eines Bratenwenders" etwa, werden durch die spontaneitas absoluta menschliche Handlungen als frei begreiflich. Es kommt also zur Differenzierung von Freiheit als Spontaneität und Willkür.

In der Kritik der reinen Vernunft wird diese Differenz kosmologisch verwertet. Hier behandelt Kant das Problem der Freiheit als absoluter Spontaneität kosmologisch. Er greift dabei schulmetaphysische Diskussionen auf, die sich anläßlich des Wolff-Lange-Streits ergaben, und zwar besonders Überlegungen in der Kosmologie der Baumgartenschen Metaphysik zur Unmöglichkeit eines infiniten Regresses der bestimmenden Ursachen oder Seinsgründen; dergleichen läuft Baumgarten zufolge auf eine Reihe zufälliger Dinge hinaus, ohne erste Ursache, von der ganzen Reihe so wenig wie von irgendeinem Teil. ${ }^{16}$ Das Denkmuster des kosmologischen Gottesbeweises fortschreibend, führt die Existenz zufälliger Wesen in der Welt auf die eines notwendigen Wesens als erster wirkender Ursache außerhalb der Welt. ${ }^{17}$ Wie bei Leibniz, Wolff u. a. ist diese erste Ursache ein notwendiges, unendliches und unveränderliches ens extramundanum, näherhin: Gott, der Urheber der zufälligen, endlichen, veränderlichen Welt. Hält man indes einen Fortgang ins Unendliche für notwendig, dann ist zwar der Rekurs auf ein Extramundanes überflüssig, zugleich aber auch eine freie Willkür dahin.

Ebendeshalb wurde der Spinozismus, das philosophische Schreckgespenst des 18. Jahrhunderts, so vehement bekämpft: ihm zufolge ist die Welt nicht zufällig, sondern notwendig, und damit auch jedes innerweltliche Geschehen. Für menschliche Freiheit wie einen außerweltlichen Gott gebe es keinen Platz. Spinozismus heißt in dieser Deutung dann soviel wie Fatalismus. Die Welt existiert notwendig, nicht zufällig, besteht ewig, nicht zeitlich, und außerhalb von ihr existiert nichts:

${ }^{16}$ ebd. $\S 380$.

${ }^{17}$ ebd. $\$ 381$. 
sie ist selbst unendlich, ihre eigene wirkende Ursache (causa sui). Schon für Wolff erweist sich nicht nur die Annahme eines extramundanen Urhebers vonnöten, sondern dieser ist zugleich als freie Ursache von allem konzipiert, die Welt Ergebnis seiner freien Wahl (des Besten, d. h. der besten aller Welten). ${ }^{18}$ Kants kosmologische oder transzendentale Freiheit ist nach diesem Denkmuster einer ersten wirkenden Ursache, die einen Zustand bzw. ersten Zustand des Weltgeschehens von selbst anfängt (KrV, B561), gestrickt. ${ }^{19}$ Er konzipiert die Welt nicht, wie Baumgarten mit Blick auf Spinoza schreibt, als unendliche Substanz, sondern eine solche Substanz als ein ens extramundanum. ${ }^{20}$

Kant, mit Baumgartens Metaphysik bestens vertraut, kam erst allmählich zu einem Konzept kosmologischer Freiheit, also zur Erkenntnis, wie es in einer Reflexion aus den 60er Jahre schon heißt, dass „das oberste Principium (der Möglichkeit) des entstehens“ die Freiheit ist (Refl. 4033, AA XVII 392). Diese erste Ursache außerhalb der Reihe der Erscheinungen findet sich in den „intellektualen“ Reihen, in der „Vernunft“; wo Vernunft, da auch ein Erstes: „Freyheit und oberstes Wesen“ (Refl. 5362, AA XVIII 162). Die „Ursache der Erscheinung ist nicht in der Erscheinung enthalten“ (Refl. 5369, AA XVIII 163). Es gibt also ein Erstes, und somit keine bloß spinozistische Unendlichkeit: transzendentale Freiheit bzw. absolute Spontaneität in der Vernunft des Menschen, folglich nicht bloß in Gott als schlechterdings erster wirkender Ursache. Das Wesen kosmologischer Freiheit als absoluter Spontaneität ist es, schlechthin erste Ursache zu sein. Freiheit ist der Ursprung der Erscheinungswelt - freilich als willkürtheoretisch konzipierte Kausalität.

Kant denkt sie als transzendentale Freiheit, die absolute Spontaneität ist: „libertas transcendentalis“, „unbedingte spontaneitaet der Handlung“ (Refl. 4759, AA XII 710). Sie bildet den ersten Grund bzw. die schlechthin erste Ursache der Reihe der Erscheinungen. „Kausalität nach Naturgesetzen“ reicht somit nicht aus, um Erscheinungen zu erklären; zusätzlich ist eine „Kausalität durch Freiheit" (KrV, B472) gefordert. Es gibt für Kant eine extramundane, unbedingte, erste Ursache der Natur, wie von Wolff cum suis behauptet: die Natur ist nicht selbst das unbedingte und notwendige Wesen, wie im Gegenbild dieser These, dem Spinozismus. Gleichwohl ist die Freiheitsproblematik für Kant trotz des dem Freiheitsbegriff nunmehr angewachsenen kosmologischen Profils immer verbunden mit einem praktischen Interesse, das ihn von Anfang an umgetrieben und das er bis in die 70er Jahre hinein im Kontext der Auseinandersetzung mit der empirischen Psychologie der Baumgartschen Metaphysik erkundet hat. ${ }^{21}$ Der transzendentale Freiheitsbegriff bildet für ihn geradezu die Grundlage des praktischen Freiheitsbegriffs, und ebenjener macht das „eigentliche Moment der Schwierigkeit“ aus (KrV, B561). Die Zurechnung einer Handlung setzt eine unbedingte Willkür voraus bzw. eine „ursprüngliche Handlung, wodurch etwas geschieht, was vorher nicht war“ (KrV, B572), und damit kosmologische Freiheit. Deren Möglichkeit wird mit Kants transzendentalem Idealismus allererst plausibel: die sensible Welt gründet in der intelligiblen; Erscheinungen sind, was sie sind, nur gemäß den Bedingungen der Vernunft.

\section{Hegel spekulative Transformation transzendentaler Freiheit}

Zwar deontologisiert Kant die Erste Ursache, die in der Schulmetaphysik Gott ist, zugunsten eines transzendentalen Idealismus der Vernunft im Menschen - er hält jedoch am praktischen Profil der Freiheitsbestimmung fest, d. h. er schreibt die tradierte Auffassung, Freiheit sei ein willkürtheoretisch

${ }^{18}$ C. Wolff: Deutsche Metaphysik, a.a.O. [Anm. 11] §§ 1080 f., 1083.

${ }^{19} \mathrm{Zu}$ diesem Schluß kommt K. Kawamura: Spontaneität und Willkür, a.a.O. [Anm. 5] 133.

${ }^{20}$ A. G. Baumgarten: Metaphysica, a.a.O. [Anm. 12] § 388.

${ }^{21}$ Noch 1798 heißt es in einem Brief an Garve über den Anlaß der Kritik der reinen Vernunft und die Freiheitsantinomie: „Nicht die Untersuchung vom Dasein Gottes, der Unsterblichkeit etc. ist der Punkt gewesen von dem ich ausgegangen bin, sondern die Antinomie der r.V.: »Die Welt hat einen Anfang -: sie hat keinen Anfang etc. bis zur vierten: Es ist Freiheit im Menschen, gegen den: es ist keine Freiheit, sondern alles ist in ihm Naturnothwendigkeit«; diese war es welche mich aus dem dogmatischen Schlummer zuerst aufweckte und zur Kritik der Vernunft selbst hintrieb, um das Skandal des scheinbaren Widerspruchs der Vernunft mit ihr selbst zu heben.“(AA XII 257 f.) 
verfaßtes Vermögen der Kausalität eines Urhebers, gar eines extramundanen Urhebers der Erscheinungswelt fort. Entsprechend ist der transzendentale Grund von naturgesetzlich Bedingtem als eine ,Folgen bewirkende Ursache` gedacht, näherhin als Willkürvermögen, als Vermögen, von selbst so oder anders handeln zu können, also aus Möglichkeiten zu wählen und sie durch Handlungen zu verwirklichen. Als Spontankausalität bewirkt sie Erscheinungen, die Kant zufolge ungeachtet der Vernünftigkeit (Vernunftbedingtheit) dieses Bewirkens hätten anders sein können, also als Wirkungen von Spontankausalität kontingenterweise so sind, wie sie sind. ${ }^{22}$ Die Beziehung von Ursache und Wirkung ist insofern äußerlicher Natur, d. h. dualistisch konzipiert, auch wenn Kant eine jedwede wirkende Ursache ihrem Charakter nach als ,gesetzlich“ bestimmt denkt. ${ }^{23}$

Die Ursprungseinheit läßt sich daher nolens volens nicht mehr als Freiheit konzipieren. Freiheit beträfe allenfalls die formale Bestimmtheit des Verhältnisses, nicht auch dessen inhaltliche Bestimmtheit. Das kosmologische Verhältnis von Erscheinungswelt und deren Grund oder Ursache ist keine der Naturgesetzlichkeit analoge Kausalität aus Freiheit; Kants Spontankausalität kann daher nicht die gesuchte Ursache der Erscheinungswelt sein. Das Kausalverhältnis ist so oder so kein absolutes Verhältnis, d.h. die so konzipierte kosmologische Einheit von Grund und Folge kein intrinsisches, sondern ein äußerliches Gefüge und deshalb nur denkbar unter Voraussetzung ursprünglicher, allerdings noch ungedachter Voraussetzungen.

Hegel thematisiert sie eigens am Ende seiner Wesenslogik und damit im Rahmen kosmologischer Konstellationen, die sich sodann als solche des ,Begriffs' erweisen: der gesuchte kosmologische Grund entpuppt sich als der (nicht-kosmologisch verfaßte, sondern jedweder Kosmologie noch zugrundeliegende) ,Begriff“. Das „Wesen“ erweist sich in Hegels Konzeption näherhin als „Grund“ der „Existenz“ bzw. der „Erscheinung“ bzw. der „Wirklichkeit“ (E §§112-159; II Zweites Buch); der Grund ist geradezu das Wesen als „Totalität“ (E §121) gesetzt. Das Grundverhältnis (von Grund und Begründetem) als inneres, „absolutes Verhältnis“ ergibt sich bei Hegel sodann aus dem kosmologischen Format des Substantialitätsverhältnisses, des Kausalitätsverhältnisses und der Wechselwirkung als Selbstverhältnis des Begriffs. Der Begriff wiederum qualifiziert sich durch seine Momente des Allgemeinen, Besonderen und Einzelnen, wodurch der Rekurs auf extern Vorgegebenes bzw. Freiheit, die bloße Spontaneität und damit Willkür bzw. Zufall ist, in den Begriff zurückgenommen wird. Der so verstandene Begriff ist für Hegel das Freie.

Mit dem Übergang vom Abschnitt ,Die Wirklichkeit‘ zur ,Lehre vom Begriff` deduziert Hegel in seiner Logik den Begriff des Begriffs und die ihm eigene Freiheit. „Der Begriff ist das Freie“ (E §160), Freiheit die ,absolute Negativität des Begriffs als Identität mit sich“ (E §382). Hegel kommt zu dieser Erkenntnis, indem er Kants kosmologischen Freiheitsbegriff und Spinozas Substanzbegriff aus ihrem gemeinsamen Grund begreift, dem Begriff als dem Freien eben. Freiheit ist ihm als solche kein Vermögen der Kausalität mehr - für Hegel eine Verstandesauffassung von Freiheit $-{ }^{24}$ sondern Bei-sich-selbst-sein-im-Anderen. Obwohl für Hegel die vielgescholtene

${ }^{22} \mathrm{Vgl}$. auch KrV, B584 f. über das Anders-sein-Können der Erscheinungen. Diese Thematik führt zum viel verhandelten Formalismus-Problem in Kants Philosophie. Vgl. dazu neuerdings meine Studien "Sittlichkeit and the Actuality of Freedom", in: The Palgrave Hegel Handbook, ed. M. Bykova and K. Westphal, Houndmills, Basingstoke, Hampshire (im Erscheinen), sowie „Die Wirklichkeit der Freiheit begreifen: Hegels Begriff von Sittlichkeit als Voraussetzung der Sittlichkeitskonzeption Kants“, in: Folia Philosophica (im Erscheinen). Hegels Begriffslehre soll die Abstraktheit überwinden, die bei Kant im Verhältnis zwischen Allgemeinem und Besonderem herrscht. (Begriffliche) Notwendigkeit (im Zusammenhang von Allgemeinem, Besonderem und Einzelnem) tritt hier entsprechend an die Stelle von Zufälligkeit.

${ }^{23}$ Wie jede „wirkende Ursache“, fasst Kant auch den „Charakter“ einer durch Freiheit wirkenden Ursache als „Gesetz“ (KrV B567), sodass einem „Subjecte der Sinnenwelt“ dadurch ein „empirischer Charakter“ wie ein „,intelligibler Charakter“ zukommt; seine „Handlungen“ sind folglich zum einen als ,Erscheinungen“ naturgesetzlich bedingt, zum anderen aber ist das Subjekt auch „Ursache jener Handlungen als Erscheinungen“ (KrV, B567).

${ }^{24}$ Freiheit als ,Vermögen“ (Freiheit als Möglichkeit), das auf einen so oder so gegebenen Stoff ,angewandt“ wird, ist Hegel eine bloße,Verstandesauffassung' dessen, was Freiheit ist (R $\S 10 \mathrm{~A}$, vgl. auch $\S 15 \mathrm{~A})$. Hegel wird wie folgt zitiert: I = Wissenschaft der Logik. Erster Teil. Hg. von Georg Lasson (Leipzig 1951); II = Wissenschaft der Logik. Zweiter Teil. Hg. von Georg Lasson (Leipzig 1951); E = Enzyklopädie der philosophischen Wissenschaften im Grundrisse (1830). Hg. von Friedhelm Nicolin und Otto 
Substanzphilosophie Spinozas ein Gegenmodell zur Konzeption einer umfassenden Freiheit als spontankausaler Grundlage der Erscheinungswelt bietet, bedarf sie, wie Hegels berühmte Formel von der Subjektwerdung der Substanz (vgl. PG 18 mit II 219) impliziert, einer subjektivitätstheoretischen Aneignung und Transformation, - jedenfalls wenn sie durch Kants transzendentale Philosophie hindurch und nicht an ihr vorbei bewerkstelligt werden soll. ${ }^{25} \mathrm{Im}$ Zuge dessen ergeben sich die „absolute Macht“ und die „blinde Notwendigkeit“, die Spinozas Substanz eignen, als die Freiheit, die das Denken, der Begriff oder die Idee ist. Die kosmologische Einheit erweist sich demzufolge als immanente Notwendigkeit des begreifenden Denkens. Wie Hegel sagt, legt das Absolute „sich selbst aus“, sodass sich die Bestimmungen des Absoluten als „identisches Setzen seiner selbst“ ergeben (II 185, vgl. 157 f., 163 f.). Diesen Manifestations- oder Selbstauslegungsprozess des Absoluten expliziert Hegel dergestalt, dass das wahrhaft absolute Verhältnis die ,gesetzte Einheit seiner in seinen Bestimmungen“ ist, d. h. der „Begriff“ (II 185, 213 ff.). Die erreichte selbstbezügliche Einheit der absoluten Substanz ist der Begriff in seiner Allgemeinheit: sich manifestierende Selbstbeziehung - Freiheit. Damit ist diejenige Freiheit, die der Begriff ist, der Grund der Wirklichkeit als Erscheinung. Der Grund der Wirklichkeit, der, mit Spinoza, zunächst Substanz schien, stellt sich heraus als jene „Freiheit, welche die Identität des Begriffs ist“ (II 218). Im Begriff „eröffnet“ sich, wie Hegel sagt, „,das Reich der Freiheit“ (II 218 f.).

Hegel denkt das kosmologische Verhältnis von Ursache und Wirkung folglich nicht mehr, wie Kant, als eine der Naturgesetzlichkeit analoge ,Gesetzlichkeit‘ (gesetzliche Notwendigkeit) aus Freiheit. Gesetzliche Notwendigkeit ist kein explicans von Freiheit mehr. Der kosmologische Grund ist weder bloße (den Einzelfall bestimmende) Notwendigkeit des Gesetzes noch gesetzlose Zufallsspontaneität. Freiheit ist nach wie vor spontane Tätigkeit. Sie ist jedoch nicht mehr durch Bestimmungen kausaler Verhältnisse wie Notwendigkeit, Zufälligkeit, Gesetz, Ursache, Wirkung charakterisiert, sondern durch die Struktur des ,spekulativen Begriffs': Allgemeines, Besonderes, Einzelnes. Das Freie, das der eine Begriff ist, bleibt als Allgemeines, Besonderes und Einzelnes in seiner Tätigkeit durchgängig ,bei sich' und ist zugleich als ,in sich` differenzierte Einheit im anderen seiner Momente. Solches Beisichselbstsein, sich ,von sich` aus, also ,spontan', ,zu sich` bestimmen, ist wahrhafte ,Selbstbestimmung'. Sie ist zugleich Vermittlung seiner Momente des Freien miteinander und sich selbst, wahrhafte ,Selbstvermittlung', und insofern immer noch Vermittlung unter eigenem (begrifflichem) Gesetz, ,Autonomie‘. Entsprechend ist das Allgemeine nicht einfach ein wie auch immer gegebenes Gesetz (Autonomie, Heteronomie), welches das Einzelne zu befolgen bemüht ist, sondern durchgängige ,Selbstbestimmung' des Allgemeinen zum Einzelnen; das Einzelne wiederum ist nicht einfachhin dem Allgemeinen unterworfen, sondern es bestimmt sich innerhalb des Allgemeinen zum Allgemeinen. Solche Freiheit spontaner Selbstbestimmung und vollständiger Selbstvermittlung als die Tätigkeitsweise des Begriffs und der ihm eigenen Notwendigkeit ist grundlegend für jedwede Spezifikation von Freiheit (namentlich geistiger Freiheit). Als ,absolute Negativität des Begriffs als Identität mit sich“ (E §382) erhält sie sich bei Hegel in allem Fortgang, sowohl innerhalb der logischen Entwicklung des Begriffs als auch des Realen.

Philosophiehistorisch gesehen, hebt Hegel im Rahmen dieser Überlegungen nicht nur den Rationalismus und Empirismus (II 184 ff.) in die Freiheit des Begriffs auf, sondern schließlich gar noch Kants transzendentale Einheit der Apperzeption (II 221 ff.). Dies ist schon deshalb ein interessanter Gesichtspunkt, weil Kants kosmologische Grundlage als Spontaneität selbst der Ausfluß jener ursprünglicheren Spontaneitätskonstellation ist. Kant hat die synthetische Einheit der Apperzeption geradezu als den höchsten Punkt des Verstandes qua Vermögen der Spontaneität (der

Pöggeler (Hamburg 1991); R = Grundlinien der Philosophie des Rechts. Hg. von Johannes Hoffmeister (Hamburg 1955). PG = Phänomenologie des Geistes. Hrsg. von Wolfgang Bonsiepen und Reinhard Heede (Hamburg 1980).

${ }^{25}$ Vgl. für eine Deutung Christian Krijnen: „Freiheit als ursprüngliche Einheit der Vernunft. Hegels begriffslogische Lösung eines Kantischen Problems“. In: Natur und Geist, hg. von Wolfgang Neuser und Pirmin Stekeler-Weithofer (Würzburg 2016: 25-52). 
Begriffe, Erkenntnisse) bzw. der Transzendentalphilosophie bezeichnet, ${ }^{26}$ d. h. als das schlechthinnige Ursprungsprinzip von Objektivität oder Gegenständlichkeit.

Nicht umsonst beginnt Hegel nach seinem wesenslogischen Durchlauf durch den Rationalismus und Empirismus die anschließende ,Begriffslogik` mit Ausführungen zum „Begriff im Allgemeinen“, in denen ausgerechnet zur Sprache kommt, was nach Hegelscher Auffassung zu den „tiefsten und richtigsten Einsichten“ von Kants Kritik der reinen Vernunft gehört: die „ursprünglichsynthetische Einheit der Apperzeption“ (II 221). Entgegen eines bloß ,,äußerlichen Verhältnisses“, habe Kant die „Einheit, die das Wesen des Begriffs“ ausmacht, als ursprünglich synthetische Einheit der Apperzeption, des „Ich denke oder des Selbstbewußtseins“ gedacht. Kant überwinde somit die Äußerlichkeit von Ich und Verstand bzw. Begriff und Gegenstand. Zu Recht betont Hegel, dass nach Kantischer Auffassung das „Object“ das ist, „in dessen Begriff das Mannigfaltige einer gegebenen Anschauung vereinigt ist“ (KrV, B137). Alle „Vereinigung“ von Vorstellungen ist „Einheit des Bewußtseins in der Synthesis derselben“ (KrV, B137); es ist also die „Einheit des Begriffs“, durch die etwas „Objekt“ ist (II 222). Die Bestimmung des Begriffs als des wahrhaft ,absoluten Verhältnisses“ führt so gesehen die Elemente der Kantischen Relationskategorien, die traditionellerweise jenes Verhältnis qualifizieren, zurück in den „Grundsatz der synthetischen Einheit der Apperception“ als „oberstes Princip alles Verstandesgebrauchs“ (KrV, B §17).

Freilich hält Hegel Kants Rückführung in die Einheit des Selbstbewußtseins als absolute Grundlage für unzureichend, weil das Verhältnis des Begriffs zur „Realität“ qua „Objektivität“ dem Begriff als „Subjektivität“ doch „,gegenübergestellt“ (II 223, vgl. 223 ff.), das Verhältnis von Anschauung und Begriff, Verstand und Sinnlichkeit, Form und Inhalt als ein bloß abstraktes Verhältnis begriffen wird (,Formalismus'). Es fehlt bei Kant somit das Hegelisch verstandene „Prinzip der Bestimmung“ (E § 508), d. h. die jedwede Äußerlichkeit aufhebende Realisierung des Begriffs durch seine Momente des Allgemeinen, Besonderen und Einzelnen. Insofern vollendet Hegels Begriffslehre, dasjenige, was er als Grund für die Schwere der Kantischen transzendentalen Deduktion ausgibt: dass über die bloße „Vorstellung“ des Verhältnisses von „Verstand“ und „Ich“ bzw. „Begriff“ zu einem „Ding und seinen Eigenschaften und Akzidenzien“ zum „Gedanken“ fortgegangen wird (II 221). Der spekulativ verstandene Begriff hat sich als diese gesuchte absolute Grundlage ergeben (vgl. auch II 220). Hegel kommt somit zu einem grundsätzlich anderen Freiheitsverständnis als Kant, indem er den willkür- und kausaltheoretischen Freiheitsbegriff überformt und zu einem nachgeordneten Begriff, der Geistphilosophie nämlich, zurückstuft. Dabei nimmt er gerade Spinoza als All-Einheitsdenker ernst und bereichert die Fatalismus-Debatte durch einen neuen und grundlegenden Gesichtspunkt.

4. Das axiotische Grundverhältnis der kantianisierendern Transzendentalphilosophie als kausaltheoretische Normativitätskonzeption

Mit seiner Kritik und Überwindung der transzendentalen Freiheitskonzeption Kants kritisiert und überwindet Hegel, systematisch gesehen, jedoch zugleich eine Auffassung, die in dieser oder jener Akzentuierung auch für die kantianisierende Transzendentalphilosophie maßgebend geworden und geblieben ist: Freiheit als Vermögen eigengesetzlicher Kausalität des tätigen Subjekts. Gerade die südwestdeutschen Neukantianer haben in ihrer bis heute leider grob unterschätzten Wertphilosophie den Finger darauf gelegt, dass Normierungsverhältnisse das fundierende Verhältnis für die gesamte Welt des Menschen ausmachen: die verschiedenen Kultur- oder Geltungssphären - Wissenschaft, Moral, Recht, Kunst, Religion usw. - sind allesamt Spezifikationen eines axiotischen

${ }^{26}$ „Und so ist die synthetische Einheit der Apperception der höchste Punkt, an dem man allen Verstandesgebrauch, selbst die ganze Logik und nach ihr die Transscendental-Philosophie heften muß, ja dieses Vermögen ist der Verstand selbst.“ (KrV, B134 Anm., vgl. $\mathrm{KrV}, \mathrm{B} \S 17$ ) 
Grundverhältnisses. ${ }^{27}$ Es ist dies ein Bedingungsverhältnis von Wert (Orientierungsdeterminante, Geltungsgesetz), wertendem Subjekt und Kulturgut. Bei dieser wertgemäßen ,Selbstgestaltung ' des Subjekts, das darin Kultur schafft, handelt es sich letztlich um eine Selbstgestaltung gemäß Werten, die mit seiner Subjektität und damit seiner Freiheit selbst verbunden sind: um autonome Werte oder Eigenwerte. Der Begriff der Selbstgestaltung betrifft also die Wertbestimmtheit ,überhaupt ` des Subjekts. Im axiotischen Grundverhältnis wird aus geltungsnoetischer Sicht, d. h. aus der Perspektive des Subjekts, das Subjekt durch den Begriff der Selbstgestaltung grundlegend bestimmt. Freiheit ist somit eine geltungsnoetische Qualifikation, eine Qualifikation des Subjekts. Dieses axiotische Grundverhältnis und die ihm eigene Idee der Selbstgestaltung des Subjekts sind wegweisend für die spätere Transzendentalphilosophie Wagners oder Flachs etwa. Wagner macht dabei wenigstens noch den Versuch, Freiheit auch als umfassende Qualifikation zu denken und sie entsprechend als eine der Grundcharaktere des Subjekts aufzufassen, und zwar: in Kantischer Weise, als „Selbstbestimmung“ des Subjekts, als Selbstbestimmung sowohl gemäß dem eigenen Entwurf als auch als Selbstbestimmung ebendieses Entwurfs selbst; ${ }^{28}$ Freiheit als Qualifikation des Subjekts wird dabei näherhin und erneut Kantisch als Thema der „Selbstgestaltung“ des Willens im Rahmen einer „Ethik“ ausgearbeitet. ${ }^{29}$ Flach hingegen faßt Freiheit von vornherein bloß als solches Bestimmungsstück des „Wollens" auf und behandelt sie, allerdings nicht als konstitutives, sondern als universal-regulatives Prinzip, im Kontext der „Lehre vom sittlichen Subjekt““ ${ }^{30}$ Bei beiden Transzendentalphilosophen jedoch liegt dieser Thematisierung das axiotische Grundverhältnis zugrunde. ${ }^{31}$ Die Welt des Menschen, der Inbegriff der verschiedenen Kultur- oder Geltungssphären, erweist sich als Inbegriff je spezifischer Ausprägungen des axiotischen Grundverhältnisses. Immer ist sie durch die Struktur eines Werte qua Geltungsgesetzlichkeiten anerkennenden (wertbezogenen) und darin Kulturgüter schaffenden Subjekts prinzipiiert. Die willkür-kausaltheoretische Modellierung bleibt also insofern strukturell erhalten, als das Subjekt sich selbst gemäß der ihm eigenen Normativität oder Wertgesetzlichkeit gestaltet, sich darin so oder so, in geltungsdifferenter Weise, zu einem Wert verhält, und damit Welt schafft. ${ }^{32}$

Im Folgenden und abschließend will ich jedoch nicht gegenwärtige Konzeptionen der Transzendentalphilosophie näher thematisieren, sondern den Versuch eines der scharfsinnigsten Neukantianer und besten ihrer Kant-Interpreten, Bruno Bauchs. Bauch hat nämlich versucht, das Verhältnis von Natur und Freiheit in einer Auseinandersetzung mit Kant zu klären. Die Probleme, die sich dabei hinsichtlich seiner eigenen Konzeption ergeben, mögen als exemplarisch für das Einheitsdenken im Rahmen des axiotischen Grundverhältnisses gelten. Diese Kantische Erblast wiegt also bis heute schwer. Unbeschadet dessen kommt dem axiotischen Grundverhältnis der kantianisierenden Transzendentalphilosophie eine außerordentliche Bedeutsamkeit zu; es hat, soweit ich sehe, nur in Hegels Ideenlehre einen wirklich ernsthaften Konkurrenten.

\footnotetext{
${ }^{27}$ Vgl. dazu Christian Krijnen: Nachmetaphysischer Sinn. Eine problemgeschichtliche und systematische Studie zu den Prinzipien der Wertphilosophie Heinrich Rickerts (Würzburg 2001: Kap. 2.3, 6.3, 7.2 f.); Christian Krijnen: Philosophie als System. Prinzipientheoretische Untersuchungen zum Systemgedanken bei Hegel, im Neukantianismus und in der Gegenwartsphilosophie (Würzburg 2008: Kap. 4.2.2; 5.4); Christian Krijnen: „Das Dasein der Freiheit. Geltungsrealisierung bei Hegel und in der kantianisierenden Transzendentalphilosophie“. In: Kulturphilosophie. Probleme und Perspektiven des Neukantianismus, hg. von Christian Krijnen, Massimo Ferrari und Pierfrancesco Fiorato (Würzburg 2014: 35-84).

${ }^{28}$ Hans Wagner: Philosophie und Reflexion (München, Basel 1980: 233).

${ }^{29}$ ebd. §26, spez. S. $244 \mathrm{ff}$.

${ }^{30}$ Werner Flach: Grundzüge der Ideenlehre. Die Themen der Selbstgestaltung des Menschen und seiner Welt, der Kultur (Würzburg 1997) Kap. 4. Vgl. auch Werner Flach: „Thematik, Methodik und Systematik der Philosophie“. In: Geltung und Begründung. Perspektiven der Philosophie Werner Flachs, hg. von Thomas Göller und Christian Krijnen (Würzburg 2007: 115150, 131-135).

${ }^{31}$ Vgl. H. Wagner: Philosophie und Reflexion, a.a.O. [Anm. 28] §25.; W. Flach: Ideenlehre, a.a.O. [Anm. 30] Kap. 3.

32 Die Freiheitskonzeption der kantianisierenden Transzendentalphilosophie ist allerdings mit grundlegenden internen Schwierigkeiten verbunden, die sich aus der Mehrdimensionalität des Freiheitsbegriffs (etwa der logischen und realen Dimension) ergeben. Vgl. dazu C. Krijnen: „Dasein der Freiheit“, a.a.O. [Anm. 27]; Christian Krijnen: „Kants Kategorien der Freiheit und das Problem der Einheit der Vernunft“. In: Die „Kategorien der Freiheit“ in Kants praktischer Philosophie. Historisch-systematische Beiträge, hg. von Stephan Zimmermann (Berlin 2016: 309-332).
} 
Konform mit der generellen südwestdeutschen Kritik an Kants Architektonik der Vernunft, moniert Bauch, dass auch Kant, wie vorwiegend in der Tradition, das Reich der Freiheit dem der Natur als dem Reich kausaler Notwendigkeit entgegensetzt. ${ }^{33}$ Zugleich jedoch wolle Kant diesen Gegensatz überwinden, wobei Bauch offenbar an Kants Kritik der Urteilskraft denkt (GE, 260): Die verschiedenen Gesetzgebungen der Natur und Freiheit beruhen auf „einem und demselben Boden der Erfahrung“, wobei die eine die andere nicht „stört“: ihr Verhältnis ist das des „Zusammenbestehens“ (KU, V 175). Dieses Zusammenbestehen ist zwar gemäß der Kritik der reinen Vernunft denkbar, es gilt allerdings noch zu begreifen, wie Freiheit in der Sinnenwelt realisiert werden kann, d. h., die Natur muss so gedacht werden können, „daß die Gesetzmäßigkeit ihrer Form wenigstens zur Möglichkeit der in ihr zu bewirkenden Zwecke nach Freiheitsgesetzen zusammenstimme“ (KU, V 176). So mag man Bauch darin folgen, dass Kant in der Kritik der Urteilskraft auf eine "Synthese“ des „ursprünglichen Gegensatzes“ aus ist, letztlich auf eine Synthese der beiden ersten Kritiken. Zugleich ist Bauch aber der Auffassung, Kant arbeite weniger diese Synthese heraus; vielmehr zeige er, dass die beiden Gesetzgebungen eher ungestört „nebeneinander als mit- und ineinander“ bestehen. Bauch zielt dabei vor allem auf die Unterscheidung von Kausalbestimmtheit (,Ursache - Wirkung') und Zweckbestimmtheit (,Zweck - Mittel') im menschlichen Handeln ab (GE, 262 ff.). Im menschlichen Handeln vereinigen sich Kausalbestimmtheit als Notwendigkeit und Zweckbestimmtheit als Freiheit.

Gegen Kant betont Bauch dabei, dass Zwecke nicht als Ursachen konzipiert werden sollten, sondern es sich genauer besehen beim Zweck-Mittel-Verhältnis um die ,Wertabhängigkeit‘ eines Wirklichen handelt. Kausal- und Wertabhängigkeit sind einerseits zu unterscheiden, anderseits jedoch ist ein Wirken nach (oder gegen) Werten immer auch kausalbedingt. Es sind aber nicht die Werte, die als Zweckursachen wirken, sondern ein Wirkliches, das Kausalgesetzen gemäß wirkt und darin zugleich wertbestimmt ist (GE, 263). Ebensolches doppelbestimmtes Wirken eines Wirklichen ist das Wirken der ,Person': die Person kann sich in ihrem immer kausalbestimmten Handeln auf Werte, d. h. Orientierungsdeterminanten vernunftbestimmter Tätigkeit, beziehen. ${ }^{34}$ Die Darstellung oder Realisierung von Werten im Wirklichen ist Hervorbringung von Wirkungen, sodass Wertverwirklichung und Kausalbeziehung, das teleologische und das kausale Verhältnis, zwar verschieden, zugleich jedoch im wertbestimmten Wirken „unabtrennbar“ sind und nur durch eine, wie es heißt, „verfehlte Abstraktion“ getrennt werden können (GE, 263). Für Bauch war Kant in gewissem Umfang einer solchen Abstraktion erlegen, mit der Folge, dass die Frage nach der Vereinigung von Kausalität aus Freiheit und Kausalität der Natur nicht zu einer „befriedigenden Auflösung“ gelangte (GE, 265 f.). Die konstitutive Bedeutung der Kategorien ist bei Kant primär Naturkonstitution, nicht Konstitution des Ganzen der Wirklichkeit. ${ }^{35}$

Bauchs Lösung für das unzureichende Einheitskonzept unterstreicht dann zunächst Kants eigene Forderung der Kritik der reinen Vernunft, die Welt müsse „als aus einer Idee entsprungen vorgestellt werden“. ${ }^{36}$ Die Welt oder Wirklichkeit ist daher immer schon ideebestimmt und in diesem Sinne nicht sinn- oder wertfrei. Sie kann vielmehr sinnvoll (oder sinnwidrig) werden. Dieses WerdenKönnen ist „zuletzt“ durch eine besondere „Spontaneität“" innerhalb des Wirklichen charakterisiert, in der der Sinn „unmittelbar“ lebendig wird: es ist die Spontaneität der „Psyche“ und damit des konkreten Subjekts oder der Person (GE, 268). Diese Spontaneität objektiviert sich „mittelbar durch

${ }^{33}$ Vgl. Bruno Bauch: Grundzüge der Ethik [= GE] (Stuttgart 1935: Kap. VII, bes. 259-281).

${ }^{34}$ GE 264 f. Vgl. zu Bauchs Konzept der Person als Wert- oder Geltungsverwirklichungsinstanz eingehend Christian Krijnen: The Very Idea of Organization. Social Ontology Today: Kantian and Hegelian Reconsiderations (Leiden, Boston 2015) Kap. 4; C. Krijnen: „Dasein der Freiheit“, a.a.O. [Anm. 27]; Christian Krijnen: „Der „Kulturimperativ“ als Geltungsverwirklichungsforderung. Hegels Formalismusproblem im Gewand kantianisierender Kulturphilosophie“. In: Kultur. Interdisziplinäre Zugänge, hg. von Hubertus Busche, Thomas Heinze u. a. (Wiesbaden, im Erscheinen).

${ }^{35}$ Vgl. ausführlich Bruno Bauch: Wahrheit, Wert und Wirklichkeit (Leipzig 1923) Teil 3.II mit 4.I, sowie Bruno Bauch: Die Idee (Leipzig 1926). Vgl. dazu C. Krijnen: Philosophie als System, a.a.O. [Anm. 27] Kap. 5.3.

${ }^{36} \mathrm{KrV}$, B843 f., vgl. GE, 268, 271 f., 280. 
die erkennende, handelnde, ästhetische usw. Tätigkeit des Subjekts“ in ein entsprechendes Werk: Wirken wie Werk haben Sinn durch das Subjekt, das sich „spontan“ auf Werte bezieht, sich auf und nach Werten richten und Werten gemäß unmittelbar wirken kann (GE, 269). Darin liegt auch, dass das Wirken des Subjekts nicht nur, wie alles Wirken, kausal bestimmt ist - als Wirken des Subjekts ist es Handeln und Schaffen. Anders gesagt: „Natur“ und „Kultur“ sind beide wirklich und insofern, als Wirklichkeit, ideebedingtheit, also nicht sinnfrei; die Natur ist jedoch frei von „Wertzielen und Aufgaben“, die Kultur nur Kultur als Beziehung des Wirklichen auf Werte. Qua Wirken steht das Kulturwirken zwar auch unter dem Kausalgesetz, anders jedoch als bloßes Naturwirken kann es sich zugleich ,unmittelbar' unter Aufgaben, Werte stellen. Als Wirken nach Werten vereinigt es in sich unmittelbar Kausalität und Freiheit. Solches Wirken muss frei sein, wodurch sich für Bauch „Spontaneität“ als „Freiheit“ auszeichnet; diese Freiheit ist kein „Freisein von der Kausalität“, sondern ein „Freisein zu Aufgaben, Zielen, Werten“ (GE, 270 f.). Durch diese Spontaneität ist das Subjekt Person und Täter einer Tat. Es ist eine Spontaneität, die „Kausalität der Freiheit“ ist (GE, 271). Bauch unterscheidet also sachlich gesehen innerhalb der einen Kausalität, die die Wirklichkeit bestimmt, zwei Arten von Kausalität, will sie jedoch versus Kant nicht als „prinzipiell abgetrennt“ verstanden wissen, sondern betont deren Zusammenhang.

Offenbar rückt Bauch damit die praktische oder personale Freiheit wieder in den Vordergrund. Während er zunächst darauf abzielte, dass Freiheit nicht einfachhin der Natur als dem Reich kausaler Notwendigkeit entgegengesetzt werden dürfe, sondern die Welt vielmehr „als aus einer Idee entsprungen“ vorgestellt werden müsse, läuft Bauchs Lösung bei Lichte besehen nicht sosehr auf diese Idee als Einheit hinaus, sondern auf das konkrete Subjekt oder die Person als Einheit von Natur und Freiheit. Sie läuft damit auf diejenige Einheit von Kausalität und Freiheit hinaus, die eine Handlung oder Tat ist, auf die ,Faktizität‘ der Vernunft also, mag Bauch auch innerhalb einer umfassenden Kausalität zwei spezifische Formen unterscheiden. Der Grund, die umfassende Kausalität, ist nicht selbst als Freiheit gedacht. Die Synthese, die Bauch anvisiert, ist die von Kausalität und Freiheit, nicht die von Natur und Freiheit. ${ }^{37}$ Es ist eine Synthese im „spontanen personalen Wirken“. Kurzum: Bauch denkt Freiheit ,in“ der Natur, nicht die Natur ,als' gegründet in Freiheit, Freiheit nicht als den kosmologischen Grund von Wirklichkeit.

Gewiß, wie Bauch sagt, ist die Natur als naturgesetzliches Dasein zwar nicht frei, jedoch ,sinnbedingt‘. Sie kann daher mittelbar ein Medium für unmittelbar wertbezogenes Wirken sein. Bauch kommt es auf die Synthese von Kausalität und Freiheit in diesem unmittelbar wertbezogenen Wirken an: auf das konkrete Subjekt qua sinnlich-geistiges Wesen. Dass unmittelbar wertbezogenes Wirken überhaupt möglich ist und die Natur mittelbar Medium für die Gestaltung der Wirklichkeit nach Maßgabe von Werten sein kann, hat für Bauch, wie gesagt, seinen „letzten und tiefsten Grund“ darin, dass Natur und Kultur, die Totalität der Wirklichkeit qua „Welt aus einer Idee entsprungen“, sinn- oder ideebedingt ist. Freiheit ist von Bauch nicht als kosmologische Grundlage der Welt konzipiert; sie ist für ihn vielmehr „kausale Bestimmtheit nach objektiven Zwecken als sich selber bestimmendes Wirken nach objektiven Zwecken, weil nach Aufgaben, Zielen und Werten“: nicht Zwecke wirken, sondern das „spontane Subjekt“ als Person wirkt nach Zwecken bzw. Aufgaben, Zielen und Werten (GE, 272). ${ }^{38}$ Die Synthese, auf die es Bauch zufolge „ursprünglich“ (GE, 275) oder „unmittelbar“ (GE, 272) ankommt, ist die von Kausalität und Freiheit im konkreten Subjekt, nicht die von Natur und Freiheit.

Zugleich jedoch denkt sich Bauch die Welt ,als aus einer Idee entsprungen“, als eine Welt, die sich in „Stufen“ entfaltet (von der anorganischen zur organischen Natur und schließlich zur

${ }^{37} \mathrm{GE}, 271 \mathrm{f} ., 275,278$

${ }^{38}$ Das konkrete Subjekt ist im südwestdeutschen Neukantianismus in logischer Hinsicht die Vermittlungsfunktion zwischen Wert und Wirklichkeit, gleich ob bei Rickert, Lask oder Bauch etwa. Vgl. dazu C. Krijnen: Nachmetaphysischer Sinn, a.a.O. [Anm. 27] Kap. 6.2.1 u. 6.2.3.3. 
Kultur) (GE, 280 f.). Diese „Selbstentfaltung“ der Idee soll die Konzeption von zwei „getrennten“ Reichen der Natur und Freiheit zugunsten eines ,mit- und ineinander“ Bestehens überwinden, sodass beide Gesetzgebungen der Vernunft bzw. Reiche der Natur und Freiheit einer grundlegenden „übergreifenden Einheit“ entstammen. Als übergreifende Einheit bringt Bauch entsprechend die Idee ins Spiel. ${ }^{39}$ Sie ist Grund und Ziel des Wirklichkeitsganzen; aus ihr entspringt in einem nichtzeitlichen Sinne die Wirklichkeit, wodurch ein zeitliches Entstehen allererst möglich wird, wie, sozusagen, aus Kants kosmologischer Freiheit die Erscheinungswelt entsteht. Freiheit indes ist für Bauch nicht dieser Ursprung. Sie ist ihm zwar keine „psychologische Eigenschaft“" oder ein seelisches „Naturvermögen“, sondern ein „Wertprädikat“ bzw., wie er mit Bezug auf Kant formuliert, ein „transzendentales Prädikat“ (GE, 283). Dennoch ist dieses transzendentale Prädikat keines jener Ursprungseinheit, die die Idee ist. Das konkrete Subjekt bildet die Synthese von Kausalität und Freiheit. Wie Bauch auch sagt: die Kultur, nicht die Natur ist der „logische Ort“ der Freiheit, und er fügt hinzu: wir begegneten diesen Gedanken bei Kant wie bei Hegel (GE, 285). Bauch unterschlägt dabei allerdings, dass die Sache bei Kant und Hegel anders gelagert ist: Freiheit als transzendentales Prädikat, d. h. transzendentale Freiheit, ist für Kant zunächst kosmologische Freiheit und als solche eine Freiheit, die der Natur und der Kultur noch zugrunde liegt. Sie hat also bei Kant nicht ihren ,logischen' Ort in der Kultur. Ebensowenig ist bei Hegel der logische Ort der Freiheit die Sphäre des Geistes: der logische Ort der Freiheit ist das Logische, d. h. die Idee im Element des reinen Denkens. Bauchs Synthese von Natur und Freiheit hingegen ist die des handelnden und darin Kultur schaffenden Subjekts. Bauch denkt Freiheit somit als praktische Freiheit, als personales Wirken, nicht als transzendentale Freiheit im kosmologischen Sinne. Menschliches Handeln vereint Natur- und Freiheitskausalität.

Diese Verwischung des Einheitsgedankens als Idee, aus der die Welt entspringt, und als Subjekt, in der sich Kausalität und Freiheit und damit, als Kultur, Natur und Freiheit vereinen, ist dem axiotischen Grundverhältnis verdankt. Hier ist die Darstellung der Idee als Tätigkeit eines konkreten Subjekts konzipiert, das sich gemäß ihm intrinsisch zugehörigen Werten gestaltet, sich selbst also gestaltet und in eins damit die Wirklichkeit als Kultur. Freiheit ist Freiheit des Subjekts; sie macht seine Möglichkeit und Aufgabe aus. Damit reproduziert sich das Kantische Modell der Freiheit als Kausalität. Sie ist nicht Manifestation eines in sich differenzierten Einen, das in allem anderen bei sich selbst ist und bleibt, sondern setzt es voraus.

\section{Literatur}

BAUCH, Bruno: Die Idee, Leipzig, 1926

: Grundzüge der Ethik, Stuttgart, 1935.

: Wahrheit, Wert und Wirklichkeit, Leipzig, 1923

BAUMGARTEN, Alexander Gottlieb: „Metaphysica“. Ed. IV, 1757. In: Kants gesammelte Schriften. Bd. I-XXIX XIV, XV, XVII, hg. von Königlich-Preußische Akademie der Wissenschaften et al., Berlin, $1900 \mathrm{ff}$.

BIANCO, Bruno: „Freiheit gegen Fatalismus. Zu Joachim Langes Kritik an Wolff“. In: Zentren der Aufklärung: I: Halle. Aufklärung und Pietismus, hg. von Norbert Hinske, Berlin, 1989, $111-155$.

BEUTEL, Albrecht: „Causa Wolffiana. Die Vertreibung Christian Wolffs aus Preußen 1723 als Kulminationspunkt des theologisch-politischen Konflikts zwischen halleschem Pietismus und Aufklärungsphilosophie“. In: Reflektierte Religion. Beiträge zur Geschichte des Protestantismus, Tübingen, 2007, 125-169.

${ }^{39}$ Vgl. noch GE, 271, 272, 278, $280 \mathrm{f}$. 
FINSTER, Reinhard: „Spontaneität, Freiheit und unbedingte Kausalität bei Leibniz, Crusius und Kant“, Studia Leibnitiana 14 (1982), 266-277.

FINSTER, Reinhard: Spontaneität und Freiheit. Eine Untersuchung zu Kants theoretischer Philosophie unter Berücksichtigung von Leibniz, Wolff und Crusius. Univ. Diss., Trier, 1984.

FLACH, Werner: Die vielfältigen Aspekte des Freiheitsbegriffs in der Philosophie Kants (unveröff. Manuskript), 2016.

: Grundzüge der Ideenlehre. Die Themen der Selbstgestaltung des Menschen und seiner Welt, der Kultur, Würzburg, 1997.

: Kant zu Geschichte, Kultur und Recht. Hrsg. von Wolfgang Bock, Berlin, 2015.

: „Thematik, Methodik und Systematik der Philosophie“. In: Geltung und Begründung. Perspektiven der Philosophie Werner Flachs, hg. von Thomas Göller und Christian Krijnen, Würzburg, 2007, 115-150.

FULDA, Hans Friedrich: „Der eine Begriff als das Freie und die Manifestationen der Freiheit des Geistes“. In: Hegel - 200 Jahre Wissenschaft der Logik, hg. von Anton Friedrich Koch, Friedrike Schick u. a., Hamburg, 2014, 15-41.

: „Freiheit als Vermögen der Kausalität und als Weise, bei sich selbst zu sein“. In: Inmitten der Zeit. Beiträge zur europäischen Gegenwartsphilosophie (FS M. Riedel), hg. von Thomas Grethlein und Heinrich Leitner, Würzburg, 1996, 47-63.

GEISMANN, Georg: „Kant über Freiheit in spekulativer und in praktischer Hinsicht“. In: Kant und kein Ende. Band 1: Studien zur Moral-, Religions- und Geschichtsphilosophie, Würzburg, 2009, 119-142.

HEIMSOETH, Heinz: „Zum kosmotheologischen Ursprung der Kantischen Freiheitsantinomie“, Kant-Studien 56 (1966), 206-229.

HEGEL, Georg Wilhelm Friedrich: Enzyklopädie der philosophischen Wissenschaften im Grundrisse (1830). Hg. von Friedhelm Nicolin und Otto Pöggeler, Hamburg, 1991.

: Grundlinien der Philosophie des Rechts.Hg. von Johannes Hoffmeister, Hamburg, 1955.

: Phänomenologie des Geistes. Hrsg. von Wolfgang Bonsiepen und Reinhard Heede, Hamburg, 1980.

: Wissenschaft der Logik. Hg. von Georg Lasson, Leipzig, 1951.

HÖFFE, Otfried: Kants Kritik der reinen Vernunft. Die Grundlegung der modernen Philosophie, München, 2003

KAWAMURA, Katsutoshi: „Eine begriffsgeschichtliche Skizze der "Willkür" im 18. Jahrhundert. Wolff, Wagner, Feder und Kant". In: Recht und Frieden in der Philosophie Kants. Akten des X. Internationalen Kant-Kongresses III, hg. von Valerio Rohden, Ricardo Terra u. a., Berlin, 2008, 173-181.

: Spontaneität und Willkür. Der Freiheitsbegriff in Kants Antinomienlehre und seine historischen Wurzeln, Stuttgart-Bad Cannstatt, 1996.

KNAPPIK, Franz; Im Reich der Freiheit. Hegels Theorie autonomer Vernunft, Berlin, 2013.

KRIJNEN, Christian: „Das Dasein der Freiheit. Geltungsrealisierung bei Hegel und in der kantianisierenden Transzendentalphilosophie“. In: Kulturphilosophie. Probleme und Perspektiven des Neukantianismus, hg. von Christian Krijnen, Massimo Ferrari und Pierfrancesco Fiorato, Würzburg, 2014, 35-84. 
: „Der „Kulturimperativ“ als Geltungsverwirklichungsforderung. Hegels Formalismusproblem im Gewand kantianisierender Kulturphilosophie“. In: Kultur. Interdisziplinäre Zugänge, hg. von Hubertus Busche, Thomas Heinze u. a., Wiesbaden, im Erscheinen.

: „Freiheit als ursprüngliche Einheit der Vernunft. Hegels begriffslogische Lösung eines Kantischen Problems“. In: Natur und Geist, hg. von Wolfgang Neuser und Pirmin StekelerWeithofer, Würzburg, 2016, 25-52.

: „Kants Kategorien der Freiheit und das Problem der Einheit der Vernunft“. In: Die „Kategorien der Freiheit“ in Kants praktischer Philosophie. Historisch-systematische Beiträge, hg. von Stephan Zimmermann, Berlin, 2016, 309-332.

: Nachmetaphysischer Sinn. Eine problemgeschichtliche und systematische Studie zu den Prinzipien der Wertphilosophie Heinrich Rickerts, Würzburg, 2001.

: Philosophie als System. Prinzipientheoretische Untersuchungen zum Systemgedanken bei Hegel, im Neukantianismus und in der Gegenwartsphilosophie, Würzburg, 2008.

: „Sittlichkeit and the Actuality of Freedom“, in: The Palgrave Hegel Handbook, ed. M. Bykova and K. Westphal, Houndmills, Basingstoke, Hampshire (im Erscheinen).

: The Very Idea of Organization. Social Ontology Today: Kantian and Hegelian Reconsiderations, Leiden-Boston, 2015

LEIBNIZ, Gottfried Wilhelm: Essais de théodicée sur la bonté de dieu, la liberté de l'homme et l'origine du mal. In: Die philosophischen Schriften von Gottfried Wilhelm Leibniz VI, hg. von Carl Immanuel Gerhardt, Hildesheim, 1978.

SCHWAIGER, Clemens: Alexander Gottlieb Baumgarten. Ein intellektuelles Porträt. Studien zur Metaphysik und Ethik von Kants Leitautor, Stuttgart-Bad Cannstatt, 2011.

WAGNER, Hans: „Die kosmologische Antithetik und ihre Auflösung in Kants Kr.d.r.V“. In: $Z u$ Kants Kritischer Philosophie, hg. von Bernward Grünewald und Hariolf Oberer, Würzburg, 2008, 82-97.

: „Kants ergänzende Überlegungen zur Möglichkeit von Freiheit im Rahmen der Auflösung der dritten Antinomie“. In: Zu Kants Kritischer Philosophie, hg. von Bernward Grünewald und Hariolf Oberer, Würzburg, 2008, 98-106.

: Philosophie und Reflexion, München, Basel, 1980.

WOLFF, Christian:Vernünfftige Gedancken von Gott, der Welt und der Seele des Menschen, auch allen Dingen überhaupt. In: Gesammelte WerkeI. 2, hg. von École, Jean et al., Hildesheim, New York, $1962 \mathrm{ff}$ 